\title{
Causas del despojo y abandono forzado de tierras en Colombia. Una mirada desde el derecho privado*
}

Causes of Dispossession and Forced Abandonment of Lands in Colombia. A Look from Private Law

William Fernando Martínez-Luna ${ }^{\mathrm{a}}$

DOI: https://doi.org/10.11144/Javeriana.vj70.cdaf

Universidad Jorge Tadeo Lozano, Colombia

williamf.martinezl@utadeo.edu.co

ORCID: https://orcid.org/0000-0002-0186-4770

Recibido: 30 Septiembre 2020

Aceptado: 20 Abril 2021

Publicado: 29 Octubre 2021

\section{Resumen:}

Teniendo en cuenta que el proceso de restitución de tierras despojadas o abandonadas, regulado por la Ley 1448 de 2011 , busca ubicar a la víctima en el mismo estado en que se encontraba antes de la situación que lo separó material y jurídicamente de sus bienes, se hace indispensable para el juez, a la hora de establecer la medida de protección, determinar el vínculo jurídico que ostentaba la víctima sobre el predio y las causas que produjeron el despojo o abandono de la tierra. De acuerdo con esto, el propósito de este trabajo es identificar cuáles han sido los principales derechos y vínculos jurídicos vulnerados a la población como consecuencia del conflicto armado interno, e indagar los motivos y modalidades que lo produjeron. Para esto se hará un análisis cuantitativo descriptivo de sentencias emitidas por los jueces y tribunales especializados en restitución de tierras.

Palabras clave: justicia transicional, restitución de tierras, conflicto armado colombiano, derecho privado.

\section{Abstract:}

Taking into account the process of restitution of dispossessed or abandoned land, regulated by Law 1448 of 2011, seeks to place the victim in the same state he was in before the situation that separated him materially and / or legally from his land, It becomes indispensable for the judge when establishing the protection measure, determining the legal link that the victim held on the property, and the causes that produced the dispossession or abandonment of the land. Accordingly, the purpose of this work is to identify which have been the main rights and / or legal links violated to the population as a result of the internal armed conflict, and investigate the reasons and modalities that produced it. For this, a descriptive quantitative analysis of sentences issued by the Judges and Courts specialized in land restitution will be made.

Keywords: transitional justice, land restitution, Colombian armed conflict, private law.

\section{Introducción}

El ser humano está íntimamente vinculado con la tierra. De esta obtiene el alimento, el agua, establece su vivienda, construye su identidad cultural, entabla relaciones sociales y familiares, en definitiva, la tierra se constituye en el pilar esencial de la vida en comunidad; esto explica el hecho reiterativo de nacer y morir en el mismo lugar.

La Corte Constitucional ha analizado en múltiples pronunciamientos el vínculo íntimo que ostentan las personas con la tierra y el territorio, estableciendo justamente la relación y diferencias entre estos dos conceptos. Al primero lo define como "la base física de un asentamiento humano" ${ }^{1}$, mientras que al segundo lo identifica con "las relaciones espirituales, sociales, culturales, económicas, entre otras, que construyen las personas y las comunidades alrededor de la tierra" ${ }^{2}$. En conclusión, tierra y territorio conforman una unidad física e inmaterial vital para el desarrollo de la persona, la familia y la sociedad ${ }^{3}$.

Partiendo de la importancia que tiene la tierra y el territorio para los ciudadanos ${ }^{4}$, la propia Corte Constitucional ha reconocido que el derecho al territorio es un derecho fundamental, no solo para las

Notas de autor

\footnotetext{
a Autor de correspondencia. Correo electrónico: williamf.martinezl@utadeo.edu.co
} 
comunidades indígenas, afrodescendientes y campesinas, sino en general para toda la población, ya que es parte esencial del desarrollo de los seres humanos y se constituye en el escenario para cumplir "sus aspiraciones más profundas"

Desde el punto de vista del derecho civil, la tierra debe considerarse como un bien inmueble, de acuerdo con lo contemplado en el artículo 656 del Código Civil ${ }^{6}$. Este cuerpo normativo reconoce que los particulares pueden tener distintas formas de vinculación con la tierra, es así que regula el derecho de usufructo, uso o habitación, servidumbre, prenda, hipoteca, posesión, tenencia y el derecho de dominio, el cual es considerado la expresión máxima del derecho a la propiedad privada, por lo tanto, la protección jurídica sobre la tierra debe provenir, en primer lugar, del propio reconocimiento del derecho a la propiedad privada ${ }^{7}$.

Las normas jurídicas colombianas, en cumplimiento y desarrollo del derecho de propiedad privada, han establecido una serie de instituciones legales (sustantivas y procesales) que permiten y protegen el acceso de los ciudadanos a la tierra. De esta manera se cuenta con el derecho de dominio, la posesión, ocupación, tenencia, etc.; asimismo, existen mecanismos legales que permiten la defensa de esos derechos y vínculos, tales como los procesos de pertenencia y posesorios. En suma, las leyes ordinarias regulan los distintos derechos que los ciudadanos poseen sobre la tierra, y establecen mecanismos procesales para defenderlos ante cualquier tipo de vulneración.

Sin embargo, el conflicto armado colombiano ha producido la violación masiva de los derechos que los ciudadanos tienen sobre la tierra, creando un escenario que desborda la capacidad del derecho ordinario para su restablecimiento. En efecto, Colombia ha sufrido en las últimas décadas un conflicto armado intenso y generalizado, que ha vinculado no solo a las instituciones de defensa del Estado, sino que ha afectado de manera directa a la población civil. Las causas del conflicto son múltiples, e incluso a día de hoy muy discutidas. Sin embargo, existe un consenso sobre un factor transversal: "la disputa por la tierra y los territorios como fuente de poder político y económico"8.

En efecto, la disputa por la tierra no solo se presenta con ocasión del conflicto armado, pues Colombia es uno de los países con más concentración de la riqueza, y, por lo tanto, uno de los más desiguales de Latinoamérica. Además, es uno de los países con mayor vulnerabilidad en cuanto a la pérdida del dominio del territorio, debido a la calidad del agua y de sus tierras, lo que ha motivado a la compra masiva de terrenos por parte de extranjeros ${ }^{9}$. Esta mezcla de factores ha permitido un escenario de lucha armada, económica y política, trayendo como consecuencia una grave afectación a la sociedad, y dejando un número muy elevado de víctimas ${ }^{10}$.

Por ende, la afectación a los derechos que la población civil mantiene sobre la tierra ha tenido como causa las estrategias violentas por parte de

actores armados interesados, o bien en la realización directa de megaproyectos agrícolas y de explotación de recursos naturales, o bien en el apoyo a ciertas empresas y actores económicos que desarrollan estos proyectos, y con los cuales se han asociado para lucrarse con los beneficios de tales actividades. ${ }^{11}$

Este conflicto ha causado aproximadamente 7,9 millones de víctimas, cuyas principales vulneraciones son aproximadamente: 6,7 millones de desplazamientos, 220.000 homicidios, 45.000 desapariciones forzadas, 30.000 secuestros, entre otras. Específicamente en el tema de tierras, el conflicto armado colombiano ha provocado el despojo o abandono de tierras por parte de más de 9000 personas, principalmente campesinos, comunidades afro e indígenas ${ }^{12}$, trayendo como consecuencia una afectación patrimonial, social e incluso cultural, agudizando "el histórico atesoramiento de la tierra en manos de terratenientes, narcotraficantes, paramilitares y grandes empresarios" 13 .

Para tratar de mitigar este daño, sanar las heridas del conflicto, procurar una reparación integral a las víctimas y aportar en la construcción de una paz estable y duradera, se hizo necesario la promulgación de la Ley 1448 de 2011 que, en el marco de la justicia transicional, reconociera el derecho que tienen las 
víctimas a la verdad, la justicia y la reparación. Respecto de este último, la Ley 1448 determina que las víctimas tienen derecho a conseguir medidas de reparación que "propendan por la restitución, indemnización, rehabilitación, satisfacción y garantías de no repetición en sus dimensiones individual, colectiva, material, moral y simbólica" (art. 69). En cuanto al tema de tierras, esto se materializa mediante un proceso autónomo, sencillo y ágil que cuenta con la participación de una Unidad Administrativa que garantiza el buen curso del proceso y que otorga a las víctimas mecanismos procesales especiales — dada su particular condición— ${ }^{14}$, que incluso "modifica muchas de las reglas clásicas del derecho civil, al establecer, por ejemplo, presunciones de ilicitud de las compras de terrenos en ciertas zonas de violencia y desplazamiento". Estos cambios se reputan necesarios para que pueda alcanzarse la restitución de millones de hectáreas del territorio nacional que han sido despojadas ${ }^{15}$. En este sentido, la Ley 1448 de 2011, en el tema específico de la reparación a las víctimas de despojo o abandono forzado, establece que el juez o tribunal determinará la medida idónea de protección para el caso concreto, atendiendo a "la vulneración en sus derechos y las características del hecho victimizante" (art. 69). Es decir, el juzgador debe analizar en su sentencia el derecho que tenía la víctima sobre el inmueble, el derecho vulnerado, su causa, para, posteriormente, establecer de manera correcta la medida de protección a la víctima.

Teniendo en cuenta lo anterior, el propósito de este trabajo es estudiar el fenómeno del despojo y del abandono forzado de la tierra en Colombia con el fin de identificar cuáles han sido los principales derechos vulnerados a las víctimas e indagar las causas que lo produjeron.

De acuerdo con esto, en la primera parte se analizan los vínculos de las víctimas antes del despojo o del abandono de sus tierras (dominio, posesión y ocupación), luego se examinan las causas y derechos vulnerados, y se finaliza con las conclusiones que arroja el estudio.

Para el cumplimiento del objetivo planteado, se realizó un análisis cuantitativo de tipo descriptivo de 198 sentencias emitidas por los jueces y tribunales especializados en restitución de tierras. Dichas sentencias fueron todas las providencias publicadas hasta $1^{\circ}$ de febrero de 2018 en la página de la Unidad de Restitución de Tierras, que resolvían una solicitud individual de restitución a particulares, y corresponden a los departamentos de Antioquia, Bolívar, Cauca, Cesar, Córdoba, Risaralda, Santander y Sucre.

Esta investigación asume, de acuerdo con la literatura y la jurisprudencia, que las víctimas se vinculan con la tierra principalmente por medio de la posesión, debido al alto grado de informalidad en el país, asimismo, que no existe una diferencia sustancial entre los casos de despojo y abandono forzado, puesto que ambas violaciones afectan por igual a la población. De la misma manera, se considera que la principal causa del despojo se materializa por medio de compraventas informales (compraventa privada, de posesión o de mejoras), y la del desplazamiento forzado mediante la propia situación de violencia.

\section{Vínculo jurídico de las víctimas con la tierra antes de la situación de despojo o abandono forzado}

El procedimiento de restitución de tierras despojadas o abandonadas forzosamente ha sacado a la luz una problemática que se ha venido agravando con el paso de los años: el alto grado de informalidad de los vínculos que los ciudadanos tienen con la tierra ${ }^{16}$. En efecto, la población colombiana, particularmente la ubicada en el sector rural, se ha relacionado con la tierra sin cumplir con los procedimientos de formalización de sus derechos. Esto ha sucedido primariamente por desconocimiento, por los elevados costos, los múltiples trámites y formalidades, la dificultad de trasladarse hasta las notarías, entre otras. Lo anterior ha derivado en la celebración de negocios jurídicos sin las solemnidades requeridas por la Ley, como compraventas o promesas de compraventas orales, compraventas en documentos privados, la omisión de la sucesión para la transferencia de los bienes del causante, etc. ${ }^{17}$ Este alto grado de informalidad produce incertidumbre y "facilita las acciones de los despojadores, haciendo más complejos, por razones probatorias, los procesos de 
restitución" ${ }^{18}$. Efectivamente, la informalidad ha representado un enorme reto para los jueces y tribunales de tierras, pues han tenido que descubrir, cuál era el verdadero derecho o vínculo que la víctima ostentaba sobre los bienes para así concretar el derecho a restituir, puesto que en no pocas ocasiones las víctimas manifiestan tener un derecho que no poseen ${ }^{19}$.

Justamente, para enfrentar la problemática de la informalidad de los derechos sobre la tierra, y realizar de manera más efectiva la restitución teniendo en cuenta las condiciones de vulnerabilidad de la población despojada o desplazada, la Ley 1448 de 2011 ha flexibilizado unas instituciones jurídicas (en materia probatoria, presunciones, principio de buena fe, cosa juzgada) con el objetivo de garantizar el restablecimiento efectivo de los derechos de las víctimas ${ }^{20}$. Asimismo, aunque son muchas las afectaciones que sufren las personas y familias que son despojadas o que deben abandonar sus inmuebles con ocasión de la violencia, la ley se limita a restablecer solo los vínculos de propiedad, posesión y ocupación de baldíos, excluyendo otras relaciones con la tierra, tales como la tenencia, y nada regula acerca de los bienes muebles despojados o abandonados.

De acuerdo con esto, y para un correcto entendimiento, no solo de los vínculos jurídicos de las víctimas con la tierra, sino para comprender la medida de reparación otorgada por el juez o tribunal, se hace necesario analizar, de manera general, las figuras de posesión, ocupación y dominio, pues se insiste, son los únicos que van a ser reparados dentro del proceso de restitución.

\section{La posesión}

Antes de abordar el estudio de la figura de la posesión, conviene aclarar si este poder jurídico puede considerarse un derecho, tal como lo manifiesta la Ley 1448 de 2011, en varios apartados del art. 72 párr. $4^{21}$ y art. 74 par.). Lo primero que ha de decirse es que en el ordenamiento jurídico colombiano la posesión debe considerarse un hecho jurídico y no un derecho real, pues este constituye un poder jurídico definitivo, mientras que la posesión constituye un poder jurídico de carácter provisional, como se verá más adelante ${ }^{22}$. La fuente de esta confusión jurídica radica en el hecho de que la posesión pueda protegerse por medio de acciones reales como los interdictos posesorios, y al ser un hecho jurídico salvaguardado por la legislación nacional "tiene las características de un derecho"23. Lo cierto es que a lo largo de los años han existido autores como Sánchez Román que han defendido la tesis de que el dominio es un derecho. En este escrito se hablará de posesión como vínculo jurídico mas no como derecho, a pesar de lo estipulado en la Ley 1448 de 2011.

La posesión es el primer vínculo legal protegido por la Ley de Restitución de Tierras, en el artículo 762 del C.C., y se define como

la tenencia de una cosa determinada con ánimo de señor o dueño, sea que el dueño o el que se da por tal, tenga la cosa por sí mismo, o por otra persona que la tenga en lugar y a nombre de él. El poseedor es reputado dueño, mientras otra persona no justifique serlo.

De acuerdo con esta disposición, el poseedor es la persona que realiza la explotación de un bien, careciendo del Derecho de dominio, como es obvio, pero comportándose ante la sociedad como si lo tuviese, es decir, considerándose como "dueño y amo del bien que ostenta" ${ }^{24}$. Para que surja la posesión de un bien se requiere la presencia del corpus y el animus, y esta puede ser regular — si se cuenta con justo título y buena fe-, o irregular — si se carece de uno o ambos requisitos-.

En materia de tierras, el fenómeno jurídico de la posesión se presenta de manera cotidiana, varias son las razones: en primer lugar, muchos de los propietarios no explotan materialmente sus predios, por lo que es frecuente que terceros realicen la tenencia con ánimo de señor y dueño. En segundo lugar, porque, no en pocos casos, los contratantes omiten el requisito de la solemnidad (escritura pública) del contrato de compraventa de bien inmueble, y tan solo señalan los derechos y obligaciones en un escrito privado, que en muchos casos 
es la promesa de compraventa. De esta manera, el pretendido comprador no adquiere el derecho de dominio, tan solo empieza a poseer el bien inmueble. En tercer lugar, también es de común ocurrencia que al morir el propietario de los bienes inmuebles rurales, sus herederos no lleven a cabo el correspondiente proceso de sucesión, por lo tanto, y a partir de ese momento, los herederos que explotan la tierra tan solo adquieren la calidad de poseedores.

Por lo anterior, aunque el poseedor se presente ante la sociedad como propietario, jurídicamente no tiene el derecho de dominio. Esto no significa que el poseedor no pueda defenderse judicialmente, por el contrario, el legislador le ha otorgado una serie de acciones que buscan salvaguardar el vínculo jurídico que ostenta, incluso si su vulneración ocurre en el marco del conflicto armado. En efecto, el poseedor de un predio que ha sido despojado u obligado a abandonarlo de manera forzosa como consecuencia directa o indirecta de la situación de violencia generalizada de acuerdo con el artículo 3 de la Ley 1448 de 2011, puede solicitar su restitución jurídica y material. Es importante destacar que, en principio, la ley pretende ubicarlo en el mismo estado físico y jurídico que presentaba antes de la situación de violencia, en otras palabras, el despojado seguirá siendo únicamente poseedor. Sin embargo, como el poseedor tiene la posibilidad de adquirir el dominio por prescripción (cumpliendo todos los requisitos que le exige el Código Civil), la situación de violencia no interrumpe el término consagrado por la Ley para la usucapión, e incluso si este término ya se hubiere cumplido, el poseedor podrá presentar la acción de pertenencia para que, adicional al restablecimiento de la posesión, se le adjudique el derecho de dominio (art. 74).

La transformación jurídica de la posesión en domino, por medio de la prescripción adquisitiva, ha sido una de las principales fuentes para obtener la propiedad en Colombia. Esto ha sido provocado por el fenómeno de la "colonización de la tierra por medio de la invasión". Este mecanismo es utilizado por personas de escasos recursos, quienes se ubican en bienes privados, empiezan a explotar dichos inmuebles, desconociendo el dominio ajeno, para obtener la posesión y posteriormente de dominio del bien. Como este comportamiento se ha venido afianzando en la población — especialmente en la rural—, el Estado colombiano, concretamente en los municipios, ha querido formalizar los derechos de los invasores, comprando estos bienes a sus dueños, convirtiéndolos así en bienes fiscales adjudicables ${ }^{25}$, y posteriormente transmitiéndoles el dominio por medio de actos administrativos a las familias que cumplan con unos requisitos establecidos por la ley colombiana ${ }^{26}$. Es decir, para obtener el dominio del bien privado que se posee, se hace necesario adelantar un proceso judicial de pertenencia, pero cuando el Estado compra el bien al particular y se lo adjudica al invasor, no solamente cambia el vínculo que este tiene sobre la tierra, sino que el procedimiento ahora es de carácter administrativo. Esta circunstancia hace que en muchos casos sea difícil establecer la relación jurídica que la víctima tenía con el bien, pues empieza siendo poseedor (cuando invade y explota el predio ajeno), luego, cuando el Estado adquiere el bien, se convierte jurídicamente en ocupante, y si finalmente se le adjudica, adquiere el derecho de dominio ${ }^{27}$.

\section{Ocupación}

El segundo vínculo ${ }^{28}$ que se protege a las víctimas del conflicto armado en Colombia es el de ocupación. Esta figura jurídica es definida por el artículo 685 del Código Civil como el modo de adquirir el "dominio de las cosas que no pertenecen a nadie, y cuya adquisición no es prohibida por las leyes o por el derecho internacional". De acuerdo con esta definición, son tres los requisitos que exige la ley para adquirir el dominio por ocupación: el primero es la aprehensión material del bien con intención de adquirirlo, el segundo es que la ocupación esté permitida por la Ley, mientras que el tercero es que la cosa carezca de dueño.

Pues bien, en materia de tierras la ocupación ha sido discutida desde antaño, principalmente en cuanto al tercer requisito, esto es, la carencia de dueño. Lo anterior porque las tierras sin dueño (bienes baldíos) se 
consideran de propiedad de la nación, conforme al artículo 675 del Código Civil "[s]on bienes de la Unión todas las tierras que estando situadas dentro de los límites territoriales carecen de otro dueño”.

De acuerdo con esto, un sector de la doctrina considera que la ocupación es un modo restringido exclusivamente a los bienes muebles, puesto que no existirían bienes inmuebles carentes de dueño ${ }^{29}$. Sin embargo, la Corte Suprema de Justicia en múltiples sentencias ha afirmado que los bienes baldíos son susceptibles de adquirirse por ocupación.

Para entender la figura de la ocupación es necesario precisar el concepto de bien baldío, pues esta relación solo se puede ejercerse cuando recae sobre este tipo de bienes inmuebles. Los bienes baldíos, como se apuntaba anteriormente, son inmuebles ubicados en el territorio colombiano que no tienen dueño, ya sea porque ningún particular ha ejercido nunca el derecho de dominio o porque se ha devuelto dicha propiedad al Estado de acuerdo con prescripciones legales. En todo caso, los bienes baldíos se consideran bienes fiscales adjudicables de propiedad del Estado, así lo ha reiterado la jurisprudencia constitucional, al respecto:

es bien claro que la Carta de 1991 reiteró la tradicional concepción según la cual pertenecen a la Nación los bienes públicos que forman parte del territorio dentro de los cuales se encuentran las tierras baldías; por tanto, bien puede la Nación reservárselas en cuanto inicial titular de los mismos, u ordenar por medio de la Ley a las entidades administrativas que se desprenden de ella, lo pertinente en cuanto al ejercicio del atributo de la personalidad de Derecho público que la caracteriza sea patrocinando o limitando el acceso de los particulares a dichos bienes. ${ }^{30}$

Por tanto, el Estado colombiano conserva los bienes baldíos para adjudicarlos a los ciudadanos que reúnan los requisitos determinados por la ley para tal fin, siendo el requerimiento más importante el de incorporar este bien inmueble a la productividad nacional mediante su explotación, pues ha de recordarse la función social que cumple la propiedad privada en el Estado colombiano ${ }^{31}$.

En consecuencia, al igual que el poseedor — quien explota la tierra ajena con ánimo de señor y dueñoel ocupante explota la tierra ajena, pero con una característica especial, esta tierra le pertenece al Estado. Es decir, el poseedor explota la tierra que le pertenece a un particular, mientras que el ocupante explota la tierra que le pertenece al Estado al carecer de dueño, pero en ambos casos, la persona que usufructúa el bien no reconoce el dominio ajeno.

En todo caso, el objetivo que persiguen tanto el poseedor como el ocupante es adquirir el derecho de dominio del bien inmueble. Sin embargo, este derecho de dominio solo puede adquirirse, en el caso del ocupante, con el título traslaticio que otorga el Estado colombiano por medio de la Agencia Nacional de Tierras, antiguo Instituto Colombiano de Reforma Agraria. De esta manera, quien estuviese ocupando un bien baldío y por la situación de violencia, que haya sido objeto de despojo o abandono, tendrá derecho a que material y jurídicamente se le restituyan sus derechos.

\section{Dominio}

Finalmente, el tercer vínculo protegido por la Ley 1448 de 2011 es el de dominio. Este es, sin lugar a dudas, el derecho real más robusto que una persona puede tener sobre una cosa, debido a que "otorga a su titular las máximas facultades que se pueden predicar sobre un bien" ${ }^{32}$, e incluso, otros derechos reales son una derivación de este ${ }^{33}$.

El Código Civil, en su artículo 669, define la propiedad o dominio como "el Derecho real en una cosa corporal, para gozar y disponer de ella, no siendo contra Ley o contra Derecho ajeno". Esta disposición tiene como origen el artículo 58 constitucional, y prescribe que el Estado colombiano garantiza la propiedad privada limitada por su función social. Esta función social de la propiedad, se ha llegado a pensar, constituye un límite al derecho de dominio, el cual era considerado desde antaño como un derecho absoluto. Sin embargo, la Corte Constitucional ha reconocido que 
en modo alguno se afecta por las limitaciones originadas en la Ley y el Derecho ajeno pues, contrario sensu, ellas corroboran las posibilidades de restringirlo, derivadas de su misma naturaleza, pues todo Derecho tiene que armonizarse con las demás que con él coexisten, o del Derecho objetivo que tiene en la Constitución su instancia suprema. ${ }^{34}$

Por tal motivo, el derecho de dominio puede llegar a restringirse por parte del legislador con el objetivo de preservar el interés general de la sociedad, no obstante, han de respetarse sus tres principales facultades, núcleo central de este derecho, a fin de que su titular pueda obtener utilidad económica que justifique su interés privado en esa propiedad.

El derecho de dominio se considera el derecho más completo que una persona pueda tener sobre un bien, porque confiere a su titular un amplio abanico de atribuciones (uso, goce y disposición) que se pueden utilizar libremente, dentro de los límites que establece la ley y los derechos ajenos. También porque es un derecho exclusivo, pues quien lo ostenta puede oponerse a cualquier intromisión u afectación en su ejercicio. Porque es perpetuo, en cuanto que permanece en la medida en que el bien sobre el cual recae no se extinga. Asimismo, porque es autónomo, pues no depende de la existencia de otro derecho principal. Finalmente, porque es un derecho real, ya que vincula a un individuo con una cosa, debiendo ser respetado por las demás personas, y su transmisión o extinción se realiza principalmente (pero no exclusivamente) por la voluntad del titular, y no por causas extrañas o la mera voluntad del tercero ${ }^{35}$.

El Código Civil, en su artículo 673, establece que son cinco los modos de adquirir el dominio: la ocupación, la accesión, la tradición, la sucesión por causa de muerte y la prescripción. De estos, son tres los que tradicionalmente han permitido la obtención de la propiedad de la tierra rural desde el punto de vista desde el derecho privado: la tradición, la sucesión y la prescripción. En efecto, por medio de la tradición se hace la entrega material acompañada de la intención de transferir el dominio; los principales medios utilizados son el contrato de compraventa de bien inmueble, el contrato de permuta y el contrato de donación.

En cuanto a la sucesión por causa de muerte, por medio de esta, se transfieren los bienes, derechos y obligaciones del difunto a quienes tienen derecho de sucederlo, de esta manera, se cambia de titular del derecho de dominio sobre la tierra, ya sea de manera individual o comunal. La donación, por su parte, es un acto jurídico (contrato) gratuito por medio del cual se transfiere irrevocablemente los bienes a otra persona. Finalmente, la prescripción, que como modo de adquirir el dominio se denomina también usucapión, "tiene la aptitud necesaria para transformar a un poseedor en titular del Derecho" 36 de dominio, cuando la cosa sea ajena, de aquellas que estén en el comercio, y se realice una posesión material ininterrumpida por el paso del tiempo (ordinaria de bienes raíces 5 años y extraordinaria 10 años), y otros requisitos de Ley.

De acuerdo con lo anterior, las víctimas del conflicto armado colombiano a las que les hayan despojado su tierra o hayan tenido que abandonarla de manera forzosa, se les protegerá el derecho o vínculo que tenían al momento de la situación de despojo o abandono, sin embargo, el Estado colombiano solo protegerá las tres relaciones analizadas. Por este motivo, en las sentencias estudiadas, se consideró necesario realizar un examen del vínculo que las víctimas exhibían sobre la tierra antes de la situación de violencia. Esto se muestra el análisis de frecuencia y porcentaje de la tabla 1.

TABLA 1.

Vínculo jurídico de la víctima con la tierra antes de la situación de violencia

\begin{tabular}{lcc}
\hline \multicolumn{1}{c}{ Derecho } & Frecuencia & Porcentaje \\
\hline Dominio & 124 & 62,6 \\
\hline Posesión & 31 & 15,7 \\
\hline Ocupación & 43 & 21,7 \\
\hline Total & 198 & 100,0 \\
\hline
\end{tabular}

Fuente: elaboración propia

Los datos de la tabla 1 dan cuenta del predominio del derecho de dominio, es decir, existen más propietarios $(62,6 \%)$ que ocupantes $(21,7 \%)$ y poseedores (15,7\%). Lo anterior indica que las víctimas del conflicto, en un alto porcentaje, tenían antes de la situación de violencia el derecho más robusto que vincula a una persona con la tierra. Este resultado es interesante, debido a que se pensaba que producto del alto grado de informalidad 
jurídica con la tierra rural, el mayor vínculo sería el de la posesión. No obstante, los datos muestran que la principal relación jurídica es de dominio seguida de la ocupación.

Asimismo, se estudió, como se muestra en la tabla 2, el motivo por el cual la víctima adquirió alguno de los tres vínculos protegidos por la ley de restitución de tierras.

TABLA 2.

Vínculo de la víctima con el predio y la fuente de su derecho

\begin{tabular}{lrrrrrrr}
\hline \multicolumn{1}{c}{ Motivo } & Dominio & $\%$ & Posesión & $\%$ & Ocupación & \multicolumn{1}{c}{$\%$} \\
\hline Adjudicación & 73 & 36,9 & 0 & 0,0 & 0 & 0,0 \\
\hline Adjudicación sin registro & 0 & 0,0 & 0 & 0,0 & 4 & 2,0 \\
\hline Compraventa & 40 & 20,2 & 1 & 0,5 & 1 & 0,5 \\
\hline $\begin{array}{l}\text { Compraventa derechos } \\
\text { sucesorales }\end{array}$ & 0 & 0,0 & 1 & 0,5 & 0 & 0,0 \\
\hline Compraventa de mejora & 0 & 0,0 & 0 & 0,0 & 2 & 1,0 \\
\hline Compraventa privada & 2 & 1,0 & 11 & 5,6 & 15 & 7,6 \\
\hline Compraventa sin registro & 0 & 0,0 & 1 & 0,5 & 0 & 0,0 \\
\hline Donación & 1 & 0,5 & 0 & 0,0 & 0 & 0,0 \\
\hline Donación sin requisitos & 0 & 0,0 & 4 & 2,0 & 0 & 0,0 \\
\hline Sucesión & 4 & 2,0 & 0 & 0,0 & 1 & 0,5 \\
\hline Invasión & 0 & 0,0 & 2 & 1,0 & 19 & 9,6 \\
\hline Ocupante hereditario & 0 & 0,0 & 0 & 0,0 & 1 & 0,5 \\
\hline Permuta & 4 & 2,0 & 0 & 0,0 & 0 & 0,0 \\
\hline Permuta privada & 0 & 0,0 & 1 & 0,5 & 0 & 0,0 \\
\hline Posedor hereditario & 0 & 0,0 & 8 & 4,0 & 0 & 0,0 \\
\hline Posesión vínculo propietario & 0 & 0,0 & 1 & 0,5 & 0 & 0,0 \\
\hline Venta de posesión & 0 & 0,0 & 1 & 0,5 & 0 & 0,0 \\
\hline Total & 124 & & 31 & & 43 & \\
\hline
\end{tabular}

Fuente: elaboración propia

Los datos de la tabla 2 muestran que el derecho de dominio es conseguido en mayor porcentaje por la adjudicación del bien por parte del Estado (36,9\%), seguido de la compraventa de bien inmueble por escritura pública (20,2\%). La posesión se adquiere principalmente por medio de la compraventa privada (5,6\%) y por herencia sin sucesión (4,0\%). La ocupación se obtiene primariamente por la invasión de los predios $(9,6 \%)$ y por compraventa privada (7,6\%), esto es, por contrato que no ha sido elevado a escritura pública.

Esta tabla permite entender que la tierra rural es adquirida principalmente por la adjudicación que hace el Estado a los ciudadanos, lo que demuestra la importancia de las políticas agrarias en el país. Sin embargo, es importante destacar que el dominio adquirido por adjudicación tuvo como fuente la invasión de predios públicos o privados, es decir, una situación de hecho y no de derecho. Si a este resultado se le suman los resultados que muestra la tabla con respecto a la posesión y la ocupación, arrojará un alto grado de informalidad del vínculo que tiene la población con la tierra. Lo que permite concluir que se está minimizando la informalidad con la tierra, mediante la adjudicación de terrenos por parte del Estado a los particulares.

\section{Despojados y desplazados de sus tierras}

Después de analizar el vínculo jurídico que ataba a las víctimas con la tierra antes de la situación de violencia, se procederá ahora a estudiar las causas que produjeron la pérdida de esos derechos. La Ley 1448 de 2011 contempla dos tipos de conductas que los victimarios despliegan para vulnerar los derechos que los ciudadanos tienen sobre la tierra: la primera de ellas es el despojo y la segunda el desplazamiento forzado. Estas conductas, aunque en muchos casos están estrechamente vinculadas, deben considerarse como fenómenos independientes, pues de esta manera se podrá "identificar la vía institucional más apta para adelantar la restitución y determinar detalladamente la reparación material o inmaterial que corresponda a cada situación" ${ }^{37}$. Se profundizará en cada una de ellas resaltando sus diferencias. 


\section{El despojo de tierras}

El despojo es una acción derivada del conflicto armado, cuyo objetivo es la privación de la propiedad, posesión y ocupación a la población, por medio de vías de hecho, negocios jurídicos con vicios del consentimiento, actos administrativos, decisiones judiciales e incluso actos delictivos, como es señalado en la Ley 1448 de 2011 en su artículo 74. Estos actos de privación de los derechos sobre la tierra no solo fueron adelantados por integrantes de grupos armados ilegales, también fueron perpetrados por personas que, aprovechando la situación de violencia en la región, consiguieron el abandono físico del bien (para conseguir la posesión), la transferencia de los derechos a bajos precios, o mediante actos de corrupción. Pero incluso el propio conflicto fue causa suficiente para que muchos de los titulares de los derechos decidieran desprenderse de ellos por un precio irrisorio, sin que existiera presión por la contraparte, con el objetivo principal de salvaguardar su vida y la de su familia, en perjuicio de su propio patrimonio.

De acuerdo con Sánchez ${ }^{38}$, las modalidades de despojo pueden dividirse en material, jurídica o mixta. La primera es conseguida a través del uso de la violencia física o moral enderezada a producir el abandono de la tierra para no solo privar al despojado de su uso material, sino provocar la pérdida de la posesión, uso y goce, la alteración de los linderos, etc. En consecuencia, esta modalidad de despojo priva al titular de la tierra de su uso corporal y, por ende, permite que de facto y por el paso del tiempo pueda perder los derechos asociados a esta (por ejemplo por la prescripción).

La segunda modalidad utiliza de manera ilegal los modos establecidos por la ley para la adquisición del dominio, tales como la ocupación y la tradición. De esta manera, se presentan compraventas, permutas, donaciones con vicios del consentimiento (dolo y fuerza, principalmente), o con ausencia total del consentimiento (mediante actos de suplantación, en muchos casos con complicidad de funcionarios públicos), compraventas con lesión enorme (el vendedor recibe un precio inferior a la mitad del justo precio), adjudicación de tierras sin el lleno de los requisitos legales, o revocatoria de dichas adjudicaciones violando los derechos de adjudicado ${ }^{39}$, entre otras. Asimismo, se incluye como despojo jurídico los inmuebles rematados por la autoridad judicial por solicitud de los acreedores (persona natural o entidad financiera) ante el incumplimiento de la obligación de pago por parte de los despojados, provocada, evidentemente, por la situación de violencia ${ }^{40}$.

En la tercera, esto es la modalidad mixta, el despojador priva a su titular del uso material de la tierra y luego utiliza mecanismos ilegales para adquirir el derecho de dominio sobre la tierra. Aquí existe un doble objetivo, la privación física y material del inmueble, por un lado, y el traspaso de los derechos, por el otro.

En todo caso, y para que exista el despojo en cualquiera de las modalidades antes mencionadas, se requiere la presencia de tres elementos. El primero de ellos es el aprovechamiento de la situación de violencia para provocar el despojo, es decir, que la pérdida del derecho por parte de la víctima estuvo enmarcada en un escenario de conflicto, que incidió directamente en la expresión del consentimiento, o en la propia presencia de este. El segundo elemento es la privación arbitraria de los vínculos que la víctima tenía sobre la tierra (dominio, posesión, ocupación). De esta manera, la víctima ya no ostenta ningún vínculo que la ate jurídicamente a su bien inmueble. Finalmente, que el acto que genera el despojo "sea de hecho, mediante negocio jurídico, acto administrativo, sentencia judicial o la comisión de delitos asociados a la situación de violencia" ${ }^{41}$.

En suma, el despojo produce la pérdida del dominio, la posesión u ocupación, sumado, en muchos casos, a la pérdida del uso material del bien, todo esto provocado por acciones enmarcadas en el conflicto armado colombiano. 


\section{El desplazamiento o abandono forzado de la tierra}

El desplazamiento o abandono forzado de la tierra es una situación fáctica de carácter transitorio o permanente en la que una persona se ve obligada a trasladarse del lugar donde reside o donde realiza sus actividades económicas habitualmente, debido a que su integridad física, su seguridad o su libertad y la de su familia, han sido vulneradas o amenazadas con ocasión del conflicto armado interno. El abandono forzado impide que la persona ejerza la administración, explotación y en general el uso y goce de sus predios, poniendo en riesgo o perdiendo los derechos que tiene sobre estos (véase Ley 1448 de 2011, arts. 60 y 74 ). Este fenómeno genera una situación de especial vulnerabilidad, puesto que la víctima se ve en la necesidad de "establecerse en un lugar extraño, sometido a toda clase de inseguridades y marginalidades, impedidos en el ejercicio efectivo de sus Derechos fundamentales y, por ende, en la adopción de un proyecto de vida" ${ }^{42}$.

Entre 1985 y 2016, en Colombia, 7.137.221 personas tuvieron que abandonar de manera forzosa sus tierras. La cifra anterior corresponde a más de 1.200 .000 familias, es decir, aproximadamente el 15,2\% de la población colombiana ${ }^{43}$.

No obstante, el desplazamiento o abandono forzado en Colombia tiene antecedentes más remotos. En efecto, la denominada "época de la violencia" (1946-1966) producida por el enfrentamiento político entre los partidos Liberal y Conservador, produjo la persecución, agresión y asesinato de aproximadamente 300.000 personas, así como la destrucción de bienes muebles e inmuebles, y el desplazamiento de al menos 2.000.000 de personas, principalmente del campo a las ciudades. Entre 1984 y 1995 ocurrió una segunda etapa de desplazamiento, llevando a más de 600.000 personas a trasladarse de su territorio de manera forzosa. Una tercera etapa se presentó desde 1995 hasta 2010, por el accionar de las guerrillas y la consolidación de los grupos paramilitares, siendo el periodo comprendido entre el 2000 y 2002 el que produjo un mayor desplazamiento de la población ${ }^{44}$.

Teniendo en cuenta los conceptos abordados, en las sentencias estudiadas se analizaron los dos tipos de afectaciones que han sufrido las víctimas del conflicto armado colombiano, como se muestra en la tabla 3. Se realizó la distribución de frecuencia y porcentaje.

TABLA 3.

Tipo de afectación de los derechos sobre la tierra

\begin{tabular}{lcc}
\hline Afectación & Frecuencia & Porcentaje \\
\hline Desplazamiento forzado & 101 & 51 \\
\hline Despojo & 97 & 49 \\
\hline Total & 198 & 100 \\
\hline
\end{tabular}

Fuente: elaboración propia

Los datos demuestran que el desplazamiento forzado es ligeramente superior (51\%) al despojo (49\%), lo cual indica que no existe una diferencia entre los dos tipos de afectaciones, comprobándose de esta manera la hipótesis planteada.

De la misma forma, se consideró necesario identificar las causas que produjeron la violación de los derechos sobre la tierra de acuerdo con el tipo de afectación. Esto se contempla en la tabla 4 mediante un análisis de frecuencia y porcentaje. 
TABLA 4.

Motivos de la afectación de los derechos de las víctimas sobre la tierra

\begin{tabular}{lrrrr}
\multicolumn{1}{c}{ Motivo } & $\begin{array}{c}\text { Desplazamiento } \\
\text { forzado }\end{array}$ & $\%$ & Despojo & $\%$ \\
\hline Abandono del bien por violencia & 101 & 51,0 & 4 & 2,0 \\
\hline Adjudicación a un tercero & 0 & 0,00 & 6 & 3,0 \\
\hline Captura ilegal fiscalia & 0 & 0,00 & 1 & 0,5 \\
\hline Compraventa & 0 & 0,00 & 54 & 27,3 \\
\hline Compraventa mejoras & 0 & 0,00 & 5 & 2,5 \\
\hline Compraventa falsa & 0 & 0,00 & 1 & 0,5 \\
\hline Compraventa parcial & 0 & 0,00 & 1 & 0,5 \\
\hline Compraventa privada & 0 & 0,00 & 7 & 3,5 \\
\hline Compraventa simulada & 0 & 0,00 & 1 & 0,5 \\
\hline Permuta & 0 & 0,00 & 1 & 0,5 \\
\hline Posesión & 0 & 0,00 & 1 & 0,5 \\
\hline Promesa de compraventa & 0 & $\mathbf{0 , 0 0}$ & 9 & 4,5 \\
\hline Remate judicial & 0 & $\mathbf{0 , 0 0}$ & 2 & 1,0 \\
\hline Revocatoria de adjudicación & 0 & $\mathbf{0 , 0 0}$ & 1 & $\mathbf{0}, 5$ \\
\hline Venta de posesión & 0 & $\mathbf{0 , 0 0}$ & 3 & 1,5 \\
\hline Total & $\mathbf{1 0 1}$ & & $\mathbf{9 7}$ & \\
\hline & & & &
\end{tabular}

Fuente: elaboración propia

La tabla 4 muestra que el desplazamiento forzado tiene como causa única la situación de violencia en la zona donde se encuentra ubicado el predio (51\%). Por su parte, el despojo es producido principalmente mediante el contrato de compraventa elevado a escritura pública (27,3\%), seguido del contrato de promesa de compraventa (4,5\%). Esto muestra con claridad que las víctimas abandonan su tierra exclusivamente por la fuerza ejercida por los actores del conflicto, y que el despojo se produce por medio de dos tipos contractuales, en los que la víctima concurre con su consentimiento viciado. El contraste chi-cuadrado indicó diferencias significativas entre los diferentes motivos y el tipo de afectación, es decir, desplazamiento forzado o despojo $\mathrm{X}^{2}(14, \mathrm{n}=198)=182.603 \mathrm{p}<, 001$.

\section{Conclusiones}

El presente trabajo tenía como pretensión principal estudiar el despojo y el abandono forzado de tierras en Colombia, para identificar cuáles han sido los derechos o vínculos vulnerados a las víctimas, indagando sus causas.

La situación de violencia generalizada en Colombia, con ocasión del conflicto armado interno, ha provocado que la población, principalmente rural, haya tenido que abandonar sus tierras o perder los derechos o vínculos que tenía sobre ella, con el objetivo de preservar su integridad física y la de su familia. Para tratar de mitigar estos daños, el Estado colombiano expidió la Ley 1448 de 2011 que dentro del marco de la justicia transicional establece unas medidas que benefician a las víctimas del conflicto armado, en sus derechos a la verdad, justicia, reparación y no repetición. En materia de tierras, esta Ley determinó que solo el dominio, posesión y ocupación serían objeto de amparo, y para tal efecto estableció unas medidas de protección que se adecuarían de acuerdo con unos principios básicos, pero en especial, atendiendo a la necesidad concreta del afectado.

De acuerdo con esto, este trabajo pretendía corroborar, en primer lugar, que la posesión era la principal forma de vinculación de los ciudadanos con la tierra, debido al alto grado de informalidad en la transmisión de la titularidad sobre los bienes inmuebles, como lo muestra la doctrina ${ }^{45}$ y la jurisprudencia ${ }^{46}$. Los datos mostraron una realidad diferente, puesto que se comprobó que el derecho de dominio es el que predomina. Sin embargo, es importante destacar que la población rural ostenta el derecho de dominio primordialmente por la adjudicación que el Estado colombiano hace de las tierras baldías, y no por relaciones privadas entre particulares. Esto es trascendental, pues si se analiza que el dominio adquirido por adjudicación tuvo como fuente la invasión de predios públicos o privados, es decir, una situación de hecho y no de derecho, se puede concluir que, en principio, sí existía un vínculo informal con la tierra, y si a este resultado le sumamos los porcentajes que muestran los datos con respecto a la posesión y la ocupación arrojarán un alto grado de informalidad del vínculo que tiene la población con los inmuebles. Lo anterior permite concluir que la 
población colombiana sí tiene una vinculación informal con la tierra, solo que esta se está superando mediante la adjudicación de terrenos por parte del Estado a los particulares.

En segundo lugar, se quería demostrar que no existe una diferencia sustancial entre los casos de despojo o abandono forzado, es decir, que ambas conductas afectaron por igual a la población colombiana. Y, en efecto, los datos demuestran que la población es afectada de manera casi equivalente por medio de estas dos conductas. Esto resulta coherente con la realidad del país, donde el justo temor a perder la vida y sus bienes hace que la población se desplace abandonándolos y decida desprenderse de su derecho con un evidente consentimiento viciado.

Lo tercero que se quería demostrar era que la principal causa de despojo se materializaba por medio de contratos de compraventas informales (como compraventas de mejoras, compraventa de posesión, compraventa privada que no ha sido elevada a escritura pública), mientras que el abandono forzado se producía por la situación de violencia generalizada. Los datos demuestran que para el caso del despojo la realidad es diferente. En efecto, se comprueba que el contrato de compraventa forzada elevado a escritura pública es la principal estrategia jurídica para despojar de la tierra a la población afectada por la violencia, y no la compraventa privada, como se pensaba por la alta informalidad en la transferencia de los derechos, principalmente en el sector rural. Esto resulta coherente con otros de los resultados obtenidos, y es que el principal derecho que tiene la población con la tierra es el dominio, y la forma más tradicional que tiene el derecho privado para transferir el dominio es justamente la compraventa de bien inmueble. Por su parte, respecto del abandono forzado, los datos comprueban que efectivamente la situación de violencia generalizada es la causa que impulsa a la población a dejar la tierra.

De acuerdo con lo anterior, este trabajo resulta pertinente, ya que muestra la realidad jurídica y fáctica del despojo y abandono forzado de tierras en Colombia, violaciones que infortunadamente continúan en la actualidad. Asimismo, tiene una pertinencia teórica, puesto que complementa los conceptos de justicia transicional con instituciones jurídicas de derecho privado, necesarias para el buen entendimiento, tanto de los derechos afectados, como de la propia medida de reparación. La pertinencia práctica de este trabajo se ve reflejada no solo en el estudio de los casos concretos de restitución de tierras, sino en la posibilidad de concretar medidas jurídicas y administrativas para que la principal causa de despojo no pueda materializarse fácilmente en el futuro. El aporte de esta investigación es que constituye un punto de partida para analizar una protección ex ante a las potenciales víctimas del despojo o abandono de tierras, puesto que la identificación de los derechos vulnerados y sus causas, posibilitan el establecimiento de mecanismos que protejan a los titulares de los derechos sobre la tierra. Este estudio se puede continuar con un análisis de las medidas de protección otorgadas a las víctimas al interior del procedimiento de restitución. También sería interesante estudiar la participación y los derechos de los opositores en el proceso, descubriendo si su actuar es de buena o mala fe.

\section{Bibliografía}

C. Flórez \& J. Mosquera \& A. Canal, Conflictos del territorio y restitución de tierras en Colombia, 0 Revista Instituto de Altos Estudios Europeos 7-21, 12 (2012).

Corte Constitucional de Colombia [C.C.], 2009, M.P.: M. J. Cepeda Espinosa, Auto 004 de 2009, [Colom.].

Corte Constitucional de Colombia [C.C.], agosto 18, 1998, M.P.: A. Martínez Caballero, Sentencia, T-427/98, [Colom.].

Corte Constitucional de Colombia [C.C.], agosto 18, 1999, M.P.: C. Gaviria Díaz Sentencia C 595/99, [Colom.].

Corte Constitucional de Colombia [C.C.], febrero 16, 2009, M.P.: J. Araujo Rentería, Sentencia T-085/09, [Colom.].

Corte Constitucional de Colombia [C.C.], febrero 22, 1996, M.P.: F. Morón Díaz, Sentencia C-060/93, [Colom.].

Corte Constitucional de Colombia [C.C.], julio 27, 2006, M.P. M. G. Monroy Cabra, Sentencia T-585/06, [Colom.].

Corte Constitucional de Colombia [C.C.], julio 9, 2014, M.P.: J. I. Palacio, Sentencia T 488/14, [Colom.]. 
Corte Constitucional de Colombia [C.C.], marzo 15, 2006, M.P.: R. Escobar Gil, Sentencia C 189/06, [Colom.]. Corte Constitucional de Colombia [C.C.], mayo 21, 1997, M.P.: F. Morón Díaz, Sentencia, T 245/97, [Colom.].

Corte Constitucional de Colombia [C.C.], octubre 2, 2012, M.P.: J. I. Pretelt Chaljub, Sentencia, T 763/12, [Colom.].

Corte Constitucional de Colombia [C.C.], octubre 23, 1997, M.P.: A. Barrera Carbonell, Sentencia C 536/97, [Colom.].

Corte Constitucional de Colombia [C.C.], septiembre 23, 2011, M.P.: J. I. Pretelt Chaljub, Sentencia T-693 de 2011, [Colom.].

Corte Constitucional de Colombia [C.C], febrero 25, 2009, M.P.: J. Araujo Rentería, Sentencia C 133/09, [Colom.]. Corte Constitucional de Colombia [C.C], mayo 5, 1994, M.P.: J. G. Hernández, Sentencia C 223/94, [Colom.].

DANE, Atlas estadístico (2019), http://geoportal.dane.gov.co/atlasestadisticoc/Pdf/Tomo_I_Demografico.pdf

J. Trujillo, Procedimiento de restitución de tierras a las víctimas del conflicto armado, 12 Revista Republicana 69-97,71 (2012).

Juzgado Civil del Circuito Especializado en Restitución de Tierras, Caucasia, Antioquia, junio 26, 2015, Sentencia rad. 051543121001-201400056-00.

Juzgado Primero Civil del Circuito Especializado en Restitución de Tierras de Antioquia, diciembre 19, 2016, Sentencia rad. 050003121101-201600005-00.

L. Velázquez, Bienes (Temis, 2000).

Ministerio de Agricultura y Desarrollo Rural de Colombia, Preguntas frecuentes sobre la restitución de tierras en la ley de víctimas (Minagricultura, 2012). https://www.restituciondetierras.gov.co/documents/10184/227457/Preg untas+Frecuentes.pdf/000dd655-83b0-422a-b163-a256001fe2bb

N. Sánchez, Tierra en transición. Justicia transicional, restitución de tierras y politica agraria en Colombia (Dejusticia, 2017).

P. Martínez, Ley de victimas y restitución de tierras en Colombia en contexto (Fdcl, 2013), https://www.tni.org/files/d ownload/martinez-ley-de-victimas-web.pdf

R. Serrano \& M. Acevedo, Reflexiones en torno a la aplicación de la Ley 1448 de 2011 y la restitución de tierras en Colombia, Revista Facultad de Derecho y Ciencias Políticas, Universidad Pontificia Bolivariana 119, 533-566, 537 (2013).

S. Chaparro, J. Revelo \& N. Sánchez, La restitución de tierrasy territorios. Justificaciones, dilemas yestrategias (Dejusticia, 2016).

Tribunal Superior del Distrito Judicial de Antioquia, Sala Primera Civil Especializada en Restitución de Tierras, diciembre 01, 2017, Sentencia rad. 050453121001-201500015-01.

Tribunal Superior del Distrito Judicial de Antioquia, Sala Tercera Civil Especializada en Restitución de Tierras, diciembre 16, 2015, M.P.: B. Yepes Puerta, Sentencia rad. 050453121002-201400020-00.

Tribunal Superior del Distrito Judicial de Cali, Sala Civil Fija de Decisión Especializada en Restitución de Tierras, marzo 15, 2016, Sentencia rad. 200013121003-201400053-01.

Tribunal Superior Distrito Judicial de Antioquia, Sala Civil Especializada en Restitución de Tierras, Sala Primera, junio 08, 2016, Sentencia rad. 050453121001-201400086-00.

Tribunal Superior Distrito Judicial de Antioquia, Sala Primera Civil Especializada en Restitución de Tierras, agosto 10, 2018, Sentencia rad. 050453121001-201502425-01.

V. Gouëset, El territorio colombiano y sus márgenes. La difícil tarea de la construcción territorial, 1 Territorios 77-94 (1999).

Y. Salinas, Dinámicas en el mercado de la tierra en Colombia, en F. Soto \& S. Gómez eds., Dinámicas del mercado de la tierra en América latina y el Caribe: concentración y extranjerización 179-207 (FAO, 2012). 


\section{Notas}

* Artículo de investigación derivado del proyecto "Relación de doble vía entre las instituciones y el proceso de paz de La Habana, perspectivas desde las ciencias sociales”, financiado por la Universidad de Bogotá Jorge Tadeo Lozano mediante su convocatoria de investigación n. $^{\circ} 13$ de 2016, identificado con código 773-13-16, adscrito al grupo de investigación Derecho y Globalización de la Universidad Jorge Tadeo Lozano.

1 Corte Constitucional de Colombia [C.C.], octubre 2, 2012, M.P.: J. I. Pretelt Chaljub, Sentencia T 763/12, [Colom.]. $2 \quad I d$.

3 No obstante esta distinción, este texto tratará estos dos conceptos como uno solo de acuerdo con la definición jurídica y privada de la tierra.

4 El territorio que conforma el Estado colombiano está compuesto por una extensión de $2.070 .408 \mathrm{~km} 2$, de los cuales 1.141.748 constituyen su área continental y 928.660 corresponde al área de soberanía marítima. Políticamente el Estado y su territorio está distribuido en 32 departamentos, 1101 municipios, donde el 70\#隹 de la población es urbana y en las zonas rurales la densidad promedio gira alrededor de diez habitantes por kilómetro cuadrado, lo que significa que la distribución de la población en el área continental colombiana es muy desigual. Véase V. Gouëset, El territorio colombiano y sus márgenes. La difícil tarea de la construcción territorial. 1 Territorios, 77-94, (Universidad del Rosario, 1999).

5 Corte Constitucional de Colombia [C.C.], septiembre 23, 2011, M.P.: J. I. Pretelt Chaljub, Sentencia T-693 de 2011, [Colom.].

6 "Inmuebles o fincas o bienes raíces son las cosas que no pueden transportarse de un lugar a otro; como las tierras y minas, y las que adhieren permanentemente a ellas, como los edificios, los árboles. Las casas y veredas se llaman predios o fundos".

7 La propiedad privada, a lo largo de la historia es concebida "como aquella relación existente entre el hombre y las cosas que lo rodean, que le permite a las personas incorporar a su patrimonio los bienes y recursos económicos que sean necesarios para efectuar todo acto de uso, beneficio o disposición que requiera", siempre y cuando se haga por los medios legítimos. Corte Constitucional de Colombia [C.C.], marzo 15, 2006, M.P.: R. Escobar Gil, Sentencia C 189/06, [Colom.]. A nivel del Derecho Internacional de los Derechos Humanos, la Declaración Universal de Derechos Humanos en su artículo 17 establece que: "1. Toda persona tiene derecho a la propiedad, individual y colectivamente. 2. Nadie será privado arbitrariamente de su propiedad”. Sin embargo, esta disposición no fue trasladada posteriormente "a los tratados de derechos humanos que convirtieron este cuerpo de normas en derechos duros. En consecuencia, no existe un reconocimiento, en el ámbito universal, del derecho a la propiedad”. N. Sánchez, Tierra en transición. Justicia transicional, restitución de tierras y politica agraria en Colombia 112 (Dejusticia, 2017). Pese a esto, en el plano regional si existe un reconocimiento al derecho a la propiedad privada. En efecto, en la Convención Americana sobre Derechos Humanos (CADH), adoptada en 1969, el artículo 21 establece que "[ $\mathrm{t}$ ]oda persona tiene derecho al uso y goce de sus bienes. La Ley puede subordinar tal uso y goce al interés social. 2. Ninguna persona puede ser privada de sus bienes, excepto mediante el pago de indemnización justa, por razones de utilidad pública o de interés social y en los casos y según las formas establecidas por la Ley. 3. Tanto la usura como cualquier otra forma de explotación del hombre por el hombre, deben ser prohibidas por la Ley”. En el ámbito interno, la Constitución colombiana incluyó dentro de los Derechos, garantías y deberes consagrados en el Título II el Derecho a la propiedad privada (art. 58), "[p] or consiguiente, las disposiciones constitucionales regulan y desarrollan lo atinente a éste Derecho y a todos aquellos Derechos adquiridos con arreglo a las Leyes civiles, siempre entendiendo que el interés privado debe ceder ante el interés público o social". Corte Constitucional de Colombia [C.C.], febrero 25, 2012, M.P.: J. A. Rentería, Sentencia C 133/09, [Colom.]. Por lo tanto, el derecho a la propiedad privada se encuentra sometido a "restricciones y limitaciones que el legislador juzgue necesario introducir en aras del superior beneficio de la comunidad”. Corte Constitucional de Colombia [C.C.], mayo 5, 1994, M.P.: J. G. Hernández, Sentencia C 223/94, [Colom.]. En efecto, la noción clásica de la propiedad basada en un concepto individualista que consideraba a este un derecho absoluto, con el paso de los años se fue transformando — siguiendo las exigencias de la justicia social y un desarrollo económico basado en la sostenibilidad- en un derecho relativo que podía ser limitado en favor de los intereses comunes de la sociedad. Corte Constitucional de Colombia [C.C.], mayo 21, 1997, M.P.: F. Morón Díaz, Sentencia T 245/97, [Colom.]. Lo anterior indica que, aunque la propiedad privada es un derecho protegido por la Constitución y la Ley, dicho derecho no es absoluto, ya que la propia Carta Magna establece que "debe cumplir una función social que implica obligaciones". De ahí que la ley contemple figuras que limiten el derecho a la propiedad privada, tales como la expropiación, la imposibilidad de variar el destino de las donaciones, la inalienabilidad, imprescriptibilidad e inembargabilidad de los bienes de uso público, la usucapión, entre otras. Corte Constitucional de Colombia [C.C], febrero 25, 2009, M.P.: J. Araujo Rentería, Sentencia C 133/09, [Colom.].

8 P. Martínez, Ley de victimas y restitución de tierras en Colombia en contexto 4 (Fdcl, 2013). https://www.tni.org/files/d ownload/martinez-ley-de-victimas-web.pdf 
C. Flórez, J. Mosquera \& A. Canal, Conflictos del territorio y restitución de tierras en Colombia. 0 Revista Instituto de Altos Estudios Europeos 7-21, 12 (2012).

10 P. Martínez, supra nota 8.

11 Corte Constitucional de Colombia [C.C.], Auto 004 de 2009, M.P.: M. J. Cepeda Espinosa, [Colom.].

12 Ministerio de Agricultura y Desarrollo Rural de Colombia, Preguntas frecuentes sobre la restitución de tierras en la ley de víctimas (Minagricultura, 2012), https://www.restituciondetierras.gov.co/documents/10184/227457/Preguntas+ Frecuentes.pdf/000dd655-83b0-422a-b163-a256001fe2bb

13 Y. Salinas, Dinámicas en el mercado de la tierra en Colombia, enDinámicas del mercado de la tierra en América latina y el Caribe: concentración y extranjerización 179-207, en F. Soto \& S. Gómez, eds. (FAO, 2012).

14 J. Trujillo, Procedimiento de restitución de tierras a las víctimas del conflicto armado, 12 Revista Republicana 69-97, 71 (2012).

15 S. Chaparro, J. Revelo \& N. Sánchez, La restitución de tierras y territorios. Justificaciones, dilemas y estrategias 14 (Dejusticia, 2016).

16 Id.

17 Véase, por ejemplo, Juzgado Civil del Circuito especializado en restitución de tierras Caucasia, Antioquia, junio 26, 2015, Sentencia rad. 051543121001-201400056-00.

18 S. Chaparro, J. Revelo \& N. Sánchez, supra nota 15.

19 Por ejemplo, las víctimas dicen tener el derecho de dominio, cuando en realidad solo ostentaban la posesión del inmueble, pues habían firmado una compraventa privada.

20 Véase Juzgado Civil del Circuito especializado en restitución de tierras Caucasia, Antioquia, junio 26, 2015, Sentencia rad. 051543121001-201400056-00.

21 "La restitución jurídica del inmueble despojado se realizará con el restablecimiento de los derechos de propiedad o posesión, según el caso [...] En el caso del derecho de posesión, su restablecimiento podrá acompañarse con la declaración de pertenencia”.

22 L. Velázquez, Bienes 122 (Temis, 2000).

23 Id.

24 Id., pág. 124.

25 Los bienes fiscales adjudicables son bienes que el Estado conserva con el fin de traspasarlos a los particulares que cumplan con determinados requisitos exigidos por la ley. Véanse algunos pronunciamientos de la Corte Constitucional sobre este tema: Corte Constitucional de Colombia [C.C.], julio 9, 2014, M.P.: J. I. Palacio, Sentencia T 488/14, [Colom.]; Corte Constitucional de Colombia [C.C.], agosto 18, 1999, M.P.: C. Gaviria Díaz, Sentencia C 595/99, [Colom.]; Corte Constitucional de Colombia [C.C.], octubre 23, 1997, M.P.: A. Barrera Carbonell, Sentencia C 536/97, [Colom.].

26 Véase Tribunal Superior del Distrito Judicial de Antioquia, Sala Tercera Civil Especializada en Restitución de Tierras, diciembre 16, 2015, M.P: B. Yepes Puerta, Sentencia rad. 050453121002-201400020-00, p. 23; Tribunal Superior del Distrito Judicial de Antioquia, Sala Primera Civil Especializada en Restitución de Tierras, diciembre 12, 2017, M.P.: J. Castillo Cadena Sentencia rad. 050453121001-201500015-01.

27 Véase Tribunal Superior Distrito Judicial de Antioquia, Sala Primera Civil Especializada en Restitución de Tierras, agosto 10, 2018, M.P.: Javier Castillo Cadena Sentencia rad. 050453121001-201502425-01.

28 Aunque la Ley 1448 de 2011 denomina la ocupación como un derecho, se debe aclarar, al igual que la posesión, que este es un hecho jurídico con protección legal y no estrictamente un derecho.

29 L. Velázquez, supra nota 26, pág. 244.

30 Véanse Corte Constitucional de Colombia [C.C.], febrero 22, 1996, M.P.: F. Morón Díaz, Sentencia C-060/93, [Colom.]; Corte Constitucional de Colombia [C.C.], agosto 18, 1999, M.P.: C. Gaviria Díaz Sentencia C 595/99, [Colom.]; Corte Constitucional de Colombia [C.C.], octubre 23, 1997, M.P.: A. Barrera Carbonell, Sentencia C 536/97, [Colom.].

31 Véase Juzgado Primero Civil del Circuito Especializado en Restitución de Tierras de Antioquia, 19/12/2016. Esta función social de la tierra se deriva del artículo 58 de la Constitución Política de Colombia.

32 Corte Constitucional de Colombia [C.C.], marzo 15, 2006, M.P.: R. Escobar Gil, Sentencia C 189/06, [Colom.].

33 L. Velázquez, supra nota 26, pág. 167.

34 Corte Constitucional de Colombia [C.C.], agosto 18, 1999, M.P.: C. Gaviria Díaz, Sentencia, C 595/99, [Colom.].

35 Corte Constitucional de Colombia [C.C.], agosto 18, 1998, M.P.: A. Martínez Caballero, Sentencia, T-427/98, [Colom.].

36 L. Velázquez, Bienes, supra nota 26, pág. 312.

37 S. Chaparro, J. Revelo \& N. Sánchez, supra nota 15, pág. 23.

38 N. Sánchez, supra nota 7.

39 Véase, por ejemplo, la sentencia del Tribunal Superior Distrito Judicial de Antioquia, Sala Civil Especializada en Restitución de Tierras, Sala Primera, septiembre 9, 2016, M.P.: J. Castillo Cadena, Sentencia rad. 
050453121001-201400086-00 y la del Juzgado Civil del Circuito Especializado en Restitución de Tierras, Itinerante, Antioquia, septiembre 9, 2016, Sentencia rad. 050453121001-201400087-00.

40 N. Sánchez, supra nota 7, pág. 158; R. Serrano \& M. Acevedo, Reflexiones en torno a la aplicación de la ley 1448 de 2011 y la restitución de tierras en Colombia, 43 Revista Facultad de Derecho y Ciencias Políticas Universidad Pontificia Bolivariana 119, 533-566, 537 (2013).

41 Véase Tribunal Superior del Distrito Judicial de Cali, Sala Civil Fija de Decisión Especializada en Restitución de Tierras, Sentencia del 15/03/2016.

42 Corte Constitucional de Colombia [C.C.], febrero 16, 2009, M.P.: J. Araujo Rentería, Sentencia T-085/09, [Colom.]; Corte Constitucional de Colombia [C.C.], julio 27, 2006, M.P. M. G. Monroy Cabra, Sentencia T-585/06, [Colom.].

43 N. Sánchez, supra nota 7, pág. 158.

44 Id.

45 S. Chaparro, J. Revelo \& N. Sánchez, supra nota 15, pág. 31.

46 Véase la jurisprudencia reiterada en: Juzgado Civil del Circuito especializado en restitución de tierras Caucasia, Antioquia, junio 26, 2015, Sentencia rad. 051543121001-201400056-00.

\section{Licencia Creative Commons CC BY 4.0}

Cómo citar este artículo: William Fernando Martínez-Luna, Causas del despojo y abandono forzado de tierras en Colombia. Una mirada desde el derecho privado, 70 Vniversitas (2021), https://doi.org/10.11144/Javeri ana.vj70.cdaf 